\title{
After criticism, more modest cancer genome project takes shape
}

An expensive federal project to identify the genetic changes that cause cancer is blazing ahead despite loud skepticism from some scientists. The US National Institutes of Health (NIH) is set to begin taking applications for the project in early March.

The scheme, dubbed The Cancer Genome Atlas, will begin with a $\$ 100$ million pilot project, but could expand to $\$ 1$ billion or more over the next decade. The goal is to scan the genome of tumors and catalog the genetic alterations associated with cancer. That information, say the project's proponents, may help researchers develop cancer drugs.

But not everyone is convinced. Some scientists have been vocal in their dissent, saying that given the NIH's shrinking budget (see below), the scheme is too expensive, is unlikely to succeed and will divert funds away from smaller, more focused studies. Smaller attempts have failed to produce usable results, they add.

"Everyone would like to know what genes cause cancer and, more importantly, what genes we could use as drug targets to kill cancer cells, but it's not clear that this kind of project will yield that information," says Steve Elledge, a Harvard University geneticist who wrote a letter to Science criticizing the project $(\mathbf{3 1 0}, 439 ; 2005)$.

The National Cancer Institute (NCI) and the National Human Genome Research Institute (NHGRI) plan to split the cost of the pilot. About one-half of the funding will go to centers that have genome sequencing capabilities. Another one-third is set aside for labs that can characterize the genome and identify which regions should be sequenced.

Because only US institutes are eligible for the funds, there are only a few centers that can take on the sequencing projects. Eric Lander, who co-chaired the committee that in February 2005 first proposed the scheme, leads one of those centers, the Massachusetts-based Broad Institute. The committee initially estimated the cost of the project at $\$ 1.35$ billion.

Lander presented the plan at a Cold Spring Harbor Laboratory meeting in June 2005. He appeared for only one session and spoke broadly about the scheme without revealing details, leading some attendees to speculate about how his institute might benefit from the project.
Lander is no longer associated with the project in any official capacity and declined to comment for this story. An independent panel of advisors will guide the project and another panel will choose which centers receive funding.

Researchers at the winning centers will begin by sequencing up to 2,000 known cancer genes in two or three tumor types, according to Anna Barker, deputy director of the NCI. If the pilot scheme is successful, the institutes could then launch a bigger project.

But focusing first on known cancer genes could make the project appear more successful than it is, Elledge says. "They need to also include a set of genes not previously implicated in cancer to get an accurate assessment of the project's potential," he says.

But some skepticism is natural when any large project is first launched, notes Aravinda Chakravarti, professor of genetic medicine at Johns Hopkins University. The Human Genome Project and the HapMap met with similar criticism when they made their debut, Chakravarti notes. "The cancer project in many ways is very similar in that it scares scientists."

Emily Waltz, New York

\section{Biomedical research faces bleak budgets}

Only pandemic flu preparedness and biodefense emerged as clear winners from President Bush's dreary 2007 budget proposal, announced on 6 February. The US National Institutes of Health (NIH), the Centers for Disease Control and Prevention and the Food and Drug Administration all face budgets that are either flat or lower than their 2006 numbers.

The figures widen the gap that has emerged over the past six years between spending on research and development in defense- and non-defense-related areas.

At the NIH, budget constraints are expected to lead to a $1.7 \%$ drop in the total number of grants it can award. Despite the bleak outlook, NIH officials say the agency will increase the number of grants to new investigators.

Bush's fiscal proposal, if adopted, would mark the fourth straight year the NIH budget has remained flat, and scientists are worried. "I lived through a similar tightening of the NIH budget in the 1980s while starting my own lab," says Joe Lipsick, a geneticist at Stanford University. "But it seems to me that this time around it's not just the funding that's tight, but rather that the culture of funding is changing. I'm not sure I'd advise my own kids to go into academic research these days."

Emily Waltz, New York
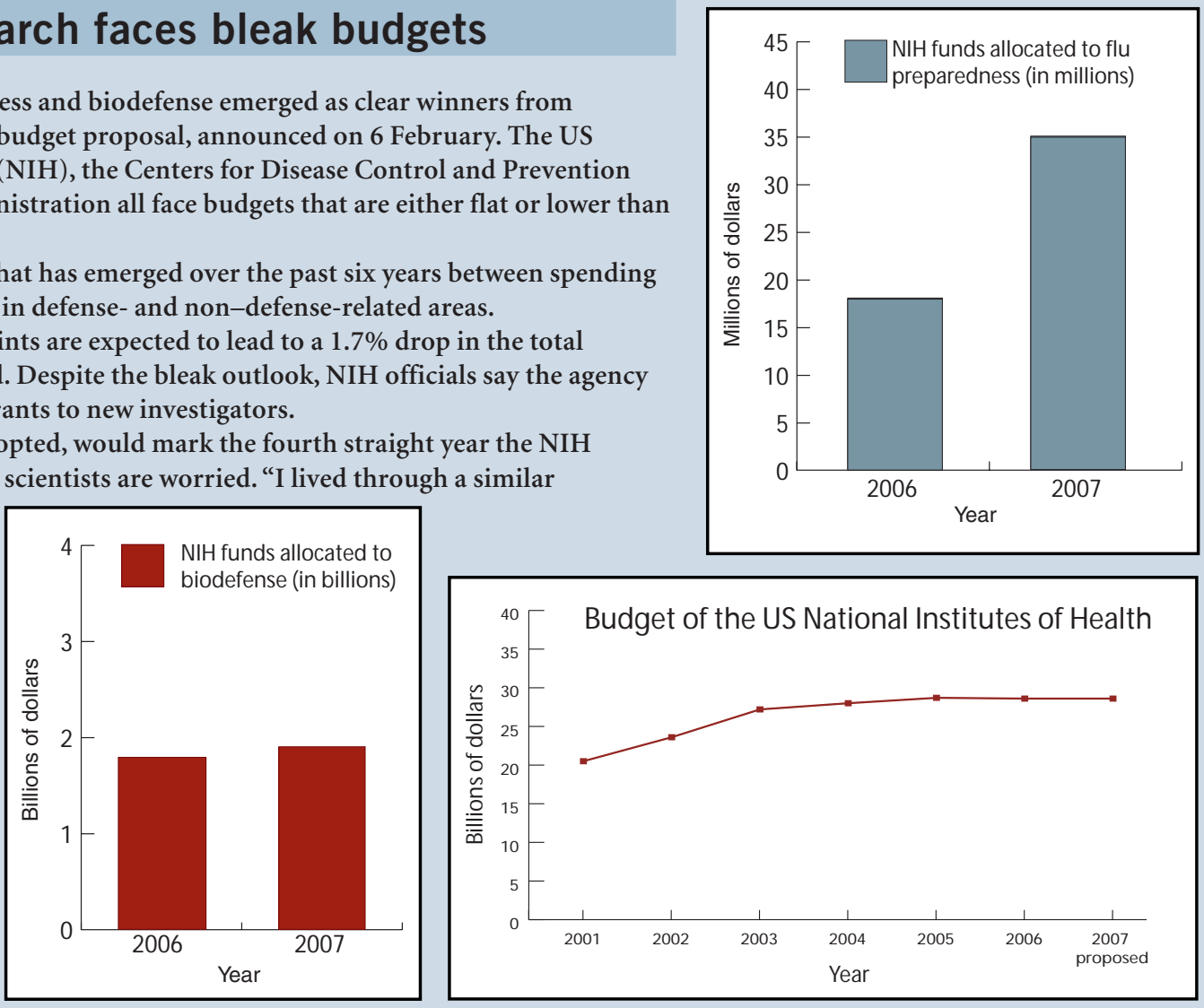